\title{
A Proposed Model for Developing the Educational Web Comics and their Impact Study on achievement and skill performance of Educational technology department students
}

\author{
By \\ Dr. Abdel-Rahman Ahmed Salem \\ Lecturer Educational Technology Department, Faculty of Specific \\ Education, Port Said University, Egypt. Director of the Computer Unit in \\ the public service at the Faculty of Specific Education Center, Port Said \\ University. Chairman of the Egyptian Association for educational computer \\ in Port Said - Egypt. E-mail: Abdou_salem@hotmail.com, website: \\ www.salem4it.com.
}

2014 


\section{1) Abstract:}

In this study, Comics is visual medium used to express educational ideas in computer upgrade and maintenance course for students of the First year, in educational technology department, in Faculty of Specific Education in Port Said - Egypt, via images with text or visual information. This type of comics is not photo Comics, it's a graphic Comics, the author use drawing by 3D studio max technology; such as: modeling, texture, lights, camera, animation and render to output this images.

The author distinguishes between two types in this study. Visual Comics and Web Comics. With Group 1, the author use Web Comic, it is published via the Internet, and the internet makes it Hyper, large size, it depends on reading and not viewing like Visual Comics. With Group 2, the author use Visual Comics, it is an interactive comic presentation, used Graphic images with mixed multimedia tools, such as text, sound, animation and interactive.

To investigate the study objectives, the author prepared some tools:

- Achievement test

- skill performance checklist

- Educational Web-comics page

- graphical Visual Comics based on web "presentation"

- graphical Hyper Comics based on web "reading"

The results showed that:

- There are differences with statistical significance at level (0.05) in the experimental groups students score average at the achievement tests of the targeted skills, due to main effects of educational comics styles (Web Comics - Visual Comics), in favor of the Visual Comics. 
- There are differences with statistical significance at level (0.05) in the experimental groups students score average at the skill performance checklist of the targeted skills, due to main effects of educational comics styles (Web Comics - Visual Comics), in favor of the Visual Comics.

According to the results, the author recommends:

- Use presentation in Visual Comics when we target the achievement objectives or the performance skill objectives.

- Mixing and using the suggested educational Comics styles, reading in Web Comics and presentation in Visual Comics, accomplishes the best educational results and encourages students to learn.

- Don't ignore the other styles that didn't use in this study like (printed Photo Comics, Hyperlink Photo Comics, Photo Visual Comics, interactive Photo Comics) and the author recommend that use this styles in other study for known its effects.

- The author recommends showing the difference between educational Visual Comics and animation in other studies to know the difference and its effects.

- Do not neglect the Benefits of web based in comics, provided by the e-learning environment, and using social network and web2 activities, due to its importance for both teachers and learners.

\section{2) Introduction:}

2/1) Theoretical Framework

2/1/1) Over View

Comics is a visual medium used to express ideas via images with text or visual information. Comics frequently takes the form of sequences 
of many of single-panel comic images from left to right layout in English, or right to left layout in Arabic. The Common usage textual tools in comics such as speech balloons, captions, and sound effects "onomatopoeia", narration, or other information. As well all other Elements such as size and arrangement of panels control narrative pacing.

The use of Comics in education based on the concept of creating engagement and motivation for students. The effectiveness of comics as medium for effective learning and development has been the subject of debate since the origin modern comic book in the 1930s (Gruenberg, 1944, pp. 204-213; Hutchinson, 1949, pp. 236-245). The use of comics in education would later attract the attention of Fredric Wertham (Wright, 2001), who noted in this time, that the use of comics in education represented "an all-time low in American science" (Dorrell, Curtis, \& Rampal, 2004).

It has been noted that the use of a narrative form such as a comic "can foster pupils' interest in science" (Negrete, \& Lartigue, 2004), and help students remember what they have learnt (Nagata, 1999) and providing a means of fostering discussion (Dorrell, Curtis, \& Rampal, 2004; Versaci, 2001, pp. 61-67). However, it also been noted that many educators remain "ambivalent" about the use of comic books as an educational tool (Norton, 2003). Comics also been used as a medium to communicate health care information on subjects such as diabetes (Pieper, \& Homobono, 2000).

The study results of Richard Mayer and Roxana Moreno (1999) show, Students viewed a computer animation depicting the process of lightning. In Experiment 1, they concurrently viewed on-screen text 
presented near the animation or far from the animation, or concurrently listened to a narration. In Experiment 2, they concurrently viewed onscreen text or listened to a narration, viewed on-screen text following or preceding the animation, or listened to a narration following or preceding the animation. Learning was measured by retention, transfer, and matching tests. Experiment 1 revealed a spatial-contiguity effect in which students learned better when visual and verbal materials were physically close. Both experiments revealed a modality effect in which students learned better when verbal input was presented auditory as speech rather than visually as text. The results support two cognitive principles of multimedia learning (Mayer, \& Moreno, 1999, p.p. 358-368).

Comics studies is becoming increasingly more common at academic institutions across the world, But in Egypt, the use of comics are very poor in education, and that was the Comics are traded commercially for some time, whether foreign translated, or Arab origin.

However, the author monitor a number of Egyptian and Arabian Studies in this area.

Including the study of Marwa Abdel-Salam (2012), she aims to develop and design an educational program using kinetic storyboard. and its impact on the acquisition of basic motor skills for kindergarten (4-6) years in of East Zagazig Education Administration, in Egypt, and the rate of change in the improvement attributed to the impact of the program using the kinetic story comic to acquire basic motor skills for kindergarten (4 -6) years of the second phase of "al-awaiel" School (Abdel-Salam, 2012).

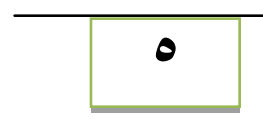


Also the study of Nasser Failkawi (2011), it studies the impact of duties kinetic comic style to learn some skills basic football deaf and dumb students in Kuwait (Failkawi, 2011).

Moreover study of Eman Badr (2010), Ended the analytical study, its results are:

- These results indicated a high percentage of children reading magazines among the sample amount to $37 \%$ always read $47 \%$ sometimes read, but about $15.5 \%$ do not read magazines.

- The most important issues favored by children in the first place in a magazine stories, and anecdotes, religious subjects, cultural topics and quizzes.

- The most favorable stories for children are the images depicted in its form, the form of characters and condors.

- First of all aspects of stories that will develop, help in the evaluation of unwanted behavior, helping to strengthen positive attitudes, ability to solve problems and ability to debate and dealing with others.

- The most important desirable behaviors that children benefited from reading stories in the consolidation came in the first thread and the federation by $100 \%$, self-reliance by $94.56 \%$, good treatment by $93.05 \%$, simplicity in dealing with others by $92.75 \%$. (Badr, 2010)

The main purpose of thesis Rania Hassan (2009) is to reach a comprehensive and inclusive theory of postmodern humor which can encompass the wide variety of humorous practices in postmodern American fiction.

The thesis also strives to highlight the reasons behind the widespread use of humor in postmodern American fiction and how it reflects the chaotic 
status quo of the postmodern society. Novels by Robert Coover, John Barth and Thomas Pynchon used as case studies to reach a final formula of a theory of postmodern humor in American fiction. Two novels were chosen from amongst the oeuvre of each novelist; one marking the beginning of his career and the other the most recent in order to cover the whole postmodern era with all its variables and intricacies (Hassan, 2009).

The study of. Mona Ali (2007) about the problem of prevalence of certain erroneous health related behaviors among hearing impaired pupils in primary education (Ali, 2007), study targets:

- Identify health-related wrong behaviors practiced by students with disabilities acoustically primary school.

- Choose from more wrong health-related behaviors common among hearing impaired pupils.

- Preparation of a collection of stories that deal with false caricature health-related behaviors common among hearing impaired pupils.

- To determine the effectiveness of the cartoon stories to modify wrong behaviors associated with the most common health hearing impaired pupils fifth grade of primary education, and the development of their awareness of those behaviors.

The study of Asmaa Morsy $\left(\gamma_{\ldots} \varepsilon\right)$ attempts to examine henry fielding theory of the comic epic in prose as a whole as mentioned in joseph Andrews and tom jones and its application to his two novels mentioned above. However, features of the ancient epic which have not been referred to in the theory of the comic epic in prose by fielding, but exist in his two novels under study will be examined. This perhaps shows 
that while expounding his own theory of the comic epic in prose, the traditional epic has influenced his mind (Morsy, 2004).

The author of the current study aims to convert Arabic courses to Comics, is also interested in producing a development model and a list of comic production standards. As well the production of comics and applied to a participants.

\section{2/1/2) Comics Definition}

The term "comics" used in the singular to refer to the medium, in the way that the words "politics" or "economics" are, so that it refers to the "comics industry" rather than the "comic industry". "Comic", as an adjective, also has the meaning of "funny", or as pertaining to comedians, which can cause confusion, and usually avoided in most cases (Lyga, \& Lyga, 2004, p. 162).

Comix is a term first popularized by cartoonists in the underground comix movement of the 1960s and 1970s in an attempt to move the word away from its etymological origins. Art Spiegelman in particular has been a proponent of its usage, hoping to highlight the fact that the medium is capable of mature, non-comedic content, as well as to emphasize the hybrid nature of the medium (Markstein, 2010).

Other terms used as synonyms for "comics" is graphic novel (Weiner, 2010), although this usage is not consistent and normally used to denote book-form comics (Markstein, 2010).

2/1/3) Comics Layout

\section{Panel}

A panel, one drawing frame contains a segment of action. A page may have one or many panels, and panels are frequently, but not always 
(Eisner, 1985, p. 45; Lee, 1978, p. 15.), surrounded by a border or outline, whose shape can altered to indicate emotion, tension or flashback sequences. The size, shape and style of a panel, as well as the placement of figures and speech balloons inside it, affect the timing or pacing of a story. Panels used to break up and encapsulate sequences of events in a narrative (Eisner, 1985, p. 28, 44, 46-47, 30, 38). What occurs in a panel may be asynchronous, meaning that not everything that occurs in a single panel necessarily occurs at one time (Duncan, \& Smith, 2009, p. 315).

\section{Gutter:}

The gutter is the space between panels (Lee, 1978, p. 15; Eisner, 1985, p. 157; McCloud, 1993, p. 66.) .

\section{Splash}

A splash or splash page is a large, often full-page illustration that opens and introduces a story ( Lee, 1978, p. 15). It is rarely less than half a page, and occasionally covers two pages (Markstein, 2010). Often designed as a decorative unit, its purpose is to capture the reader's attention, and can used to establish time, place and mood (Eisner, 1985, p. 62).

\section{Spread}

A spread is an image that spans more than one page. The two-page spread is the most common, but there are spreads that span more pages, often by making use of a foldout (or gatefold).

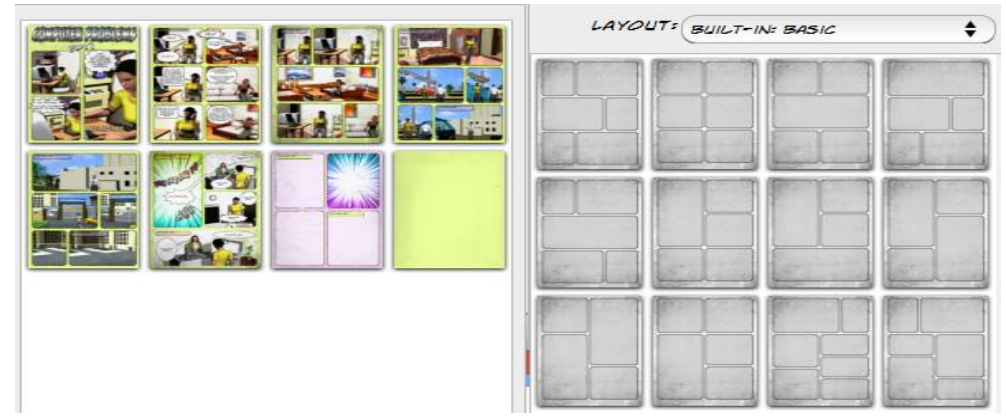


Figure (1) the basic Comics layout in "comic life" tool

In previous figure (1), we can show the basic Comics layout in "comic life" tool, the Author use it in this study.

2/1/4) Comics Text Elements

The three main text elements, balloons, captions and Sound Effects, can easily added to comic pages. In next figure (2), we can differentiate between them in this study.

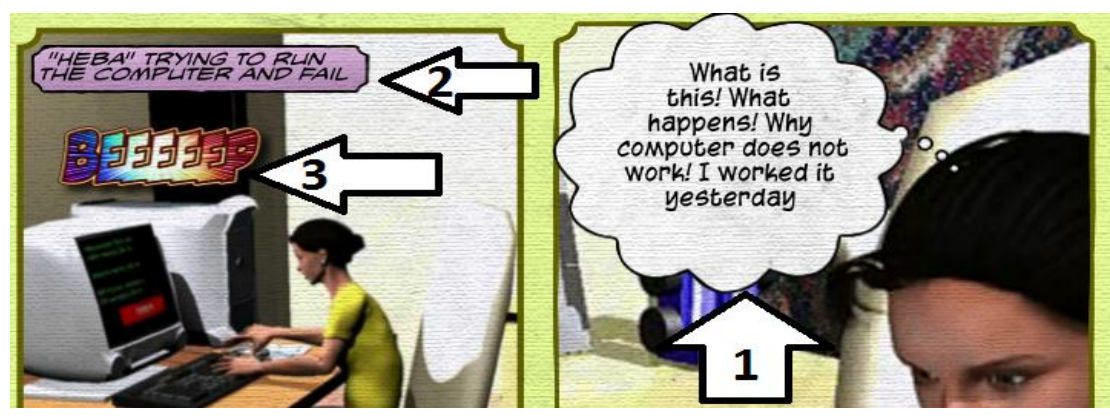

Figure (2) three main text elements, balloons: 1, and captions: 2, sound effect: 3

Speech balloons are a graphic convention used most commonly in comic, In this study, the author use some of Speech balloons style examples:

- A speech balloon or the bubble is a speech indicator, containing the characters' dialogue. The indicator from the balloon that points at the speaker is called a pointer or tail ( Lee, 1978, p. 15; Markstein, 2010; Eisner, 1985, p. 62; Dawson, 2010, p. 112). The speech balloon bridges the gap between word and image "the word made image", as expressed by Pierre Fresnault-Druelle (Carrier, 2001, p. 28). In early renderings, speech balloons were no more than ribbons emanating from their speakers' mouths, but as it evolved and became more sophisticated, it became a more 
expressive device. Its shape came to convey meaning as well (Eisner, 1985, p. 27). A thought balloon contains copy expressing a character's unvoiced thoughts, usually shaped like a cloud, with bubbles as a pointer (Lee, 1978, p. 15). Emotions can be expressed by the shape of the balloon-spiked balloons can indicate shouting, and balloons "dripping" balloons can indicate sarcasm (Eisner, 1996, p. 174). Below, some of Speech Balloons examples in this study:

- Thought Balloons: Text in a thought balloon can be italicized. The tail on a thought balloon made up of smaller bubbles and should point towards a character's head.

- Radio Balloons: These also called, "electric balloons". Whenever speech transmitted through a radio, TV, telephone, computers or any type of speaker.

- Joining Balloon To Balloon: when a character says two separate ideas expressed one after the other, but the author did not use the second instance is when two characters are speaking in a panel and the conversation goes back and forth between them. Balloons directly joined together are generally of the same thought process. Two or more expressions that are of the same topic should executed this way. This rule is most often broken when space constraints do not permit it and have to use a connector. (Piekos, 2013)

- Sound Effects: Onomatopoeia defined as a word, which imitates the natural sounds of a thing, it frequently employed in comics (Literary 
devices, 2014). Sound effects or onomatopoeia are words that mimic sounds. They are non-vocal sound images, from the subtle to the forceful (Duncan, \& Smith, 2009, p.p. 318,156). Below, some of Sound Effects examples in this study:

- Beeeep: the computer sound alarm, and in other frames refer to the cars audio alert, the author differentiates between them by writing size.

- Tec: Clicking sound on the computer keyboard

- Voooo: The accelerated Cars voice

- Taq: sound of knocking on the doors

- Zeeee: Opening doors Voice

- Captions: There are two type of caption the author used it in current comics study; Location \& Time and Spoken. In general we can find five types of captions in comics study Location \& Time, Internal Monologue, Spoken, and Editorial. Captions generally used for narration purposes. They are generally rectangular and positioned near the edge of the panel. Often they also colored to indicate the difference between them and the bubbles used by the characters, which are usually white (Piekos, 2013). In a caption, words appear in a box separated from the rest of the panel or page, usually to give voice to a narrator, but sometimes used for the characters' thoughts or dialogue (Lee, 1978, p. 15; Lyga, \& Lyga, 2004, p. 161).

In next figure (3), we can differentiate between Speech balloons, Captions, and Sound Effects in this study. 

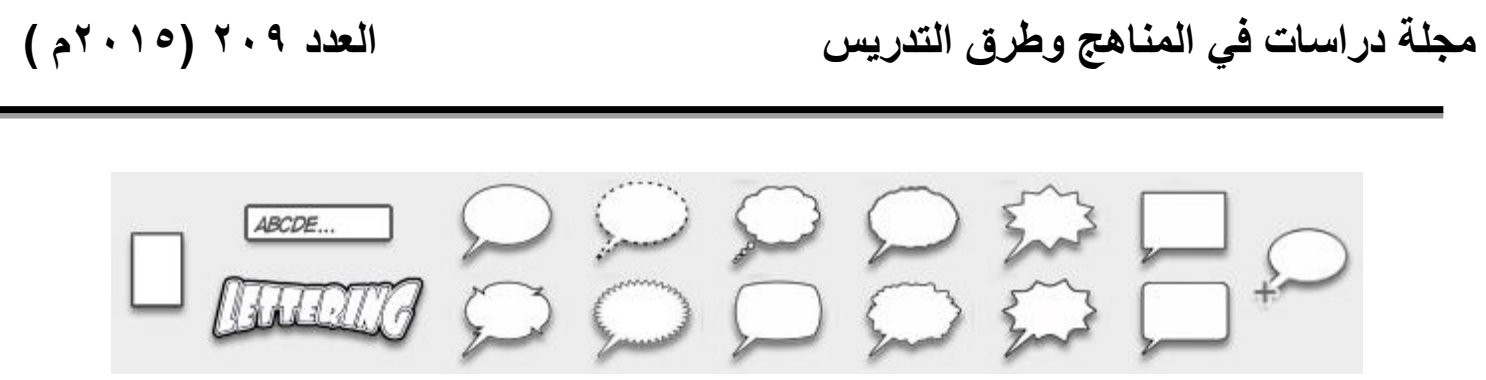

Figure (3) the most common speech balloons

2/1/5) Comics Team work

In this study, all steps of a comic production down to the editing, publishing and distribution done by author. In general, the work distribution of several professional persons, sometimes comics work divided up into different specialties, like; Writer, Painter and Publisher. The team work on the collective team is the best methods to work. The team consists of:

- Cartoonist

- Artist

- Painter

- Inker

- Colourist

- Writer

- Specialist comics computer program "comic life3 program in this study"

- Publisher "Website publisher in this study"

2/2) Definition of term

\section{Comics}

Comics is visual medium used to express ideas via images with text or visual information.

\section{Photo Comics}


Photo Comics is a type of Comics, using a film or television episode Snapshots as a real pictures and using this pictures with the narrative text by speech balloons to reflect the dialogue.

\section{Graphic Comics}

Graphic Comics is a type of Comics, using drawing and Coloring and using this images with the narrative text by speech balloons to reflect the dialogue.

\section{Visual Comics}

Visual Comics is an interactive presentation or interactive comics, featuring mostly static graphics, most often using real pictures and Graphic images with mixed multimedia tools, such as text, sound, animation and interactive.

\section{Web Comics}

Web Comics published via the Internet on the World Wide Web. As they are not limited by the size and shape of a physical page, they can make use of different sizes and dimensions. These comics are also used of multimedia elements, such as sound and animation.

\section{Hyperlink Comics}

Hyper comics refers to a variation of web comic, it coming from the merging of the term "hypertext" with "comics" to navigate and browse in comic content And not just publishing on the Web. Hyper comics also used features of web comic, including multimedia such as sound, animation. In addition, it have hyperlinks and non-linear.

2/3) Purpose of the study 
- Design model for the development of interactive Comics and novels in the educational process explains steps of production and its sequence.

- Propose a set of production standards to be guided and directed to specialists.

- Production interactive comics and novels according to the proposed model.

- Examine the impact of different style of provided comics on development of skill performance.

2/4) Importance of the study

This study and its findings can contribute to the following:-

- Produce a collection of interactive Comics and novels in educational, specialization in the education technology.

- Recruitment and use one of the most important techniques in education: educational computer games and 3D animation, to help learners and researchers.

- Activating interactive Comics and novels in educational process through the study of its elements.

2/5) Problem of the study

First - formerly an author working experience

Through the author experiences in 2D and 3D graphics, which precedent in the author's Master Degree (2005), the author's PhD (2009) and the author's publication of a study paper on the comics (2011) that Recommended to development educational curriculum using Comics. And the needs to employ the new technology of interactive web-comics in new 
studies, because of the limited of Arab studies and researches in this field. (Salem, 2005; Salem, 2009; Salem, 2011).

Secondly - studies and previous research

Based on the previous research studies results related to the subject of current study, listed through the theoretical framework of the study, the author found that: at research studies of the educational media, the author didn't sufficiently address the subject of comics Interactive in general, and published them on the Web in particular; and that this area needs more researches and studies.

Based on the studies, confirmed previous research, and related research topic, the author can say that: the studies and previous research did not assert or suggest any of the previous studies on the pattern of the ideal educational comics.

Thirdly - Survey study done by the author in 2013

Opinion poll done by the author through a personal interview for 20 of teachers and 20 of learners about the patterns of comics, and whether they're already needed in the educational process or not?

Where the opinions of students assembled in the poll, it's mostly concerned with the answers of specific questions:

- Are the comics used in the educational process?

They pointed out that $95 \%$ of the teachers in scientific fields that; they do not use comics in teaching, only as far as the textbook found, while $80 \%$ indicated teachers of literary disciplines they are using comics within the textbook, if any. 
They pointed out that $90 \%$ of the learners; enjoy many stories pictured outside the study and it is not used in the educational process, especially in the scientific disciplines, while did not confirm this only $10 \%$.

- Do the students and teachers who are studying using comics prefer certain patterns of comics?

They pointed out that $97 \%$ of the teachers; would prefer the presence of comics in the educational process regardless of its kind, while $3 \%$ indicated that they see it as an educational tool, like any other means.

They pointed out that $80 \%$ of the learners; prefer the presence of comics in the educational process regardless of its kind, while $20 \%$ indicated that; they see it as an educational tool, like any other means.

- Do the students and teachers who are studying using comics prefer specific fields to others?

They pointed out that $98 \%$ of the teachers are interest in this area and their support for the existence in all fields and filling the gaps in the disciplines, while $2 \%$ did not show them any interest in the subject.

They pointed out that $75 \%$ of the learners need for such quality of education with entertainment in all disciplines, while $25 \%$ of them didn't care.

2/6) Questions of the study

- What is the proposed design for the Comics development model in the educational process?

- What are the proposed criteria for the Comics development in the educational process?

- What is the effect of using comics in the skill performance development? 
- Is there a relationship between the different pattern of web-comics and the development of skill performance?

2/7) Hypotheses of the study

- There are no differences with statistical significance at level (0.05) in the experimental groups students score average at the achievement tests of the targeted skills, due to main effects of Educational comics styles (Web Comics - Visual Comics).

- There are no differences with statistical significance at level (0.05) in the experimental groups students score average at the skill performance checklist of the targeted skills, due to main effects of Educational comics styles (Web Comics - Visual Comics).

\section{3) Methodology Procedures}

Study procedures include the following elements.

3/1) Design and production of the experimental processing.

3/2) Building study tools and measurement and validation.

3/3) Procedure exploratory experiment.

3/4) Procedure the study experience.

The following is an explanation of these steps in detail:

3/1) Design and production of the experimental:

3/1/1) the Proposed Model, Criteria and Standards for Developing the Comic

In the following pages, the author show the four general steps for proposed model, analysis, design, development, and publishing. In this pages author also explanation of the proposed production model details and its criteria and standards.

3/1/1/1) Comics Analysis 


\section{3/1/1/1/1) Data collection}

In the analysis phase is written the basic components which are prerequisites for the production of comics. A comic is a narrative that is told through events, frames, or panels. As you brainstorm ideas for comic, thinking about: settings, character, conflict, themes, and tone, all this elements Described through plot a narrative structure "dramatic structure", which divides a story into five parts, like the five acts of a play. These parts are exposition (of the situation); rising action (through conflict); climax (or turning point); falling action; and resolution (How to Make a Comic, 2014; How to Draw Comics, 2014; University of South Carolina, 2006; University of Illinois: Department of English, 2006). In next figure (4), we can differentiate between five parts of Gustav Freytag's pyramid "theory of dramatic structure".

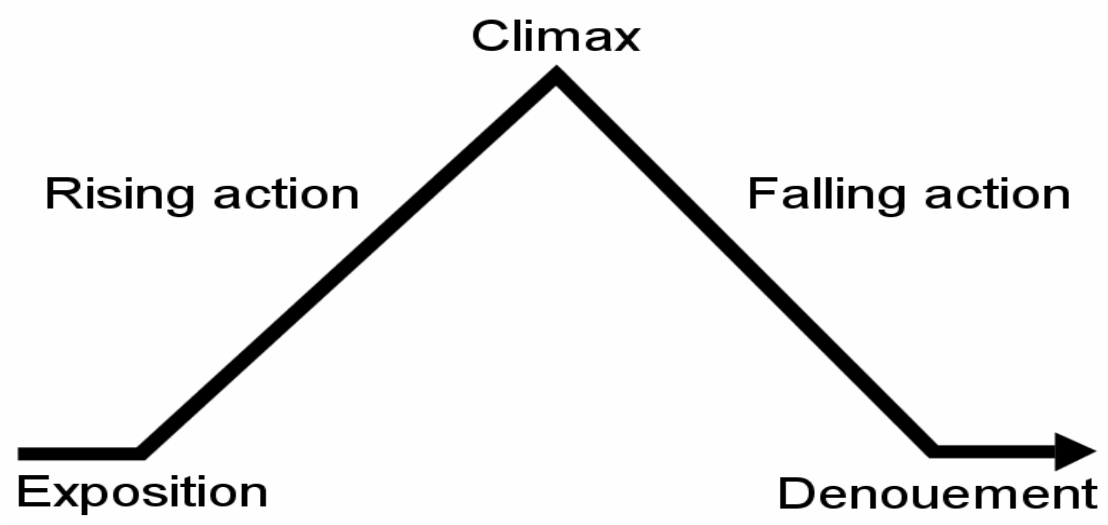

Figure (4) Gustav Freytag's pyramid "theory of dramatic structure"

- Determine main idea and goals: Ideas can summarize comic concepts that aren't presented as mental images. This term refers to a general concept of comic. It leads the author to know the content idea, it's necessary to deal with this idea. In this study, the general concept is 
development of skill performance for computer teachers, the author derived General goals and objectives from the content idea.

- Setting: Every story is set somewhere. Even if the background is just plain white, that is still a setting. The setting is the backdrop for the actions of characters, and depending on story can be an integral part of the exposition "narrative", The exposition is the portion of a story that introduces important background information to the audience; for example, information about the setting, events occurring before the main plot, characters' back stories, And other (Kaplan SAT Subject Test, 2009, p. 60). Exposition can be conveyed through dialogues, flashbacks, character's thoughts, background details, inuniverse media or the narrator telling a back-story (Dibell, 1988, p. 51; Morrell, 2006, p. 64).

- Characters: comic need actors for story. Characters move the action, they speak the dialogue, and they are who the reader connects with. Develop characters over time; this is especially important for strips that form longer narratives (Wikihow, 2014).

- Conflict: Every story needs a conflict to drive it. This is the basis of the story, the "why" of what characters are doing. This can be as simple as startup computer and checking the email or as complex as Repair computer problems and breakdowns.

- Themes: The most common contemporary understanding of theme is an idea or point that is central to a story, which can often be summed in a single word (e.g. love, death, betrayal, learning, Success). Typical examples of themes of this type are conflict between the individual and society; Humans in case of continuous learning; 
humans in conflict with technology (Kirszner, \& Mandell, 1994, pp. 2-4). The theme of comic is what drives the day-to-day creation. Theme will also dictate audience. If writing a comedy strip, what are the nature of the jokes? If you are writing a love story, what are the lessons of love learned? (Wikihow, 2014)

- Tone: This is the feelings and sense of comic. Are you writing an education or something else? Is story more of a drama or comedy? Maybe you are looking at doing educational cartoons. Possibilities are endless. Tone will be expressed through dialogue, narrative text, and visuals (Wikihow, 2014). In this study, the author use educational story, the story combine education "Repair the computer problems" with drama. Combine learning and teaching with drama and comedy; make it better.

\section{3/1/1/1/2) Experts Team:}

One of the best ways to make comics feel "true" is to write about what you know and have experience in this field. This will also help to keep own voice in writing, and prevent you from copying too much from other comics. And author in this study has a good experience in computer upgrade and maintenance course, the author employing this course in many of the studies, as he taught this course for many years. In this part, the author if have not knowledge can consult with the experts in the educational course. The author experience also appear in the use of the program "Comic Life 3". Experience here are two types of production experience in using the software "Tone" and expertise in the Course "Story". Anyway the Author work in this study as an expert and Write what he knows in all the functions of the working group following: 
- Writer

- Autodesk 3D Studio Max Specialist

- Comics computer program "comic life3" Specialist

- Publisher "publish on www.salem4it.com Website in this study" 3/1/1/1/3) Comic style

The comic style in this study, should match maker's tone and the story. The style of a comic is the first thing that is going to jump out to students and readers. Here are a few examples of different educational comic styles, the author used it in this study:

- Web Comics

- Visual Comics

There are exceptions to this, however, as with every rule when it comes to creating something (Wikihow, 2014). Choose a style that matches both the tone of story and the image you have in head (Florence, 2014). But educational dramas usually necessitate a more elaborate visual style than a comedy or the normal dramas.

\section{3/1/1/1/4) Comic format}

There are no set conventions when it comes to format, though comics typically fall into three categories: Single frame, Strip, and Page length (comic book). Experiment with different formats until find one that suits story, characters, and setting (Wikihow, 2014; Florence, 2014).

- A single frame comic is typically reserved for comedy. These comics do not require much setup, and rely on visual gags and one or two lines of dialogue. It can be difficult to form a narrative using single frames, so most can be read in any order. Political comics are also typically one or two frames. 
- A comic strip is a sequence of frames. There is no set length for a strip, though most are usually one or two lines of 2-4 frames each. This is one of the most popular formats for many "web comics" and daily funnies, as they allow for narrative development but are still short enough to produce regularly.

- A comic page is a larger undertaking than a strip. Having the whole page to work not only provides more freedom to manipulate frames, but also means that you need more content per page. Creating full pages is typically the result of making a comic book or graphic novel, where you are telling a longer, more cohesive story. The author used it in this study.

3/1/1/1/5) Evaluation and validation of analysis steps

Self-review for all of these Consecutive steps:

- Determine Main Idea

- Determine Experts Team

- Determine Content

- Deriving Goals And Objective From Educational Content

- Determine Settings

- Determine Character

- Determine Conflict

- Determine Comic Themes

- Determine Comic Tone

- Determine Comic Style

- Determine Comic Format

- Write Draft Story

- Write Draft Story With Dramatic Structure 
- Preparation for writing script

3/1/1/6) Alternative available

- Available Product: a choice limited to one of two or more possibilities, of Comics and the selection of which is useful in this topic.

3/1/1/2) Comics Design

Creating the Rough Draft for comics. By following these steps.

3/1/1/2/1) write main script

Story in this study will need a script or words. To begin comic, create a rough draft or a script, the length and detail of the script will vary depending on the style of comic. A single frame comic may only have a line or two. Regardless, write it out to help you judge how well the story reads.

- Write script as a sequence of frames. Treat each frame as a separate scene to help you manage the flow of the story.

- Make sure that the dialogue does not dominate the frame. Comics are a visual medium, and so a lot of actions and implied meanings will be coming through the illustrations. Don't let the text overpower the images. (Creative Comic Art, 2014)

3/1/1/2/2) Creating storyboard - Sketch out the frames

At the early stages of drawing comic, you'd need to want to sketch out the frames for the comic. In the beginning, do not worry about accurate sizes, details, or quality. You will be creating storyboard thumbnails. Do this as you write the script? This very rough sketch will help you visualize the flow of the comic. (Butler, 2014) 
- Focus on how characters will be placed in the frame, where the action is occurring, and how the dialogue will fit in the drawing.

- Once thumbnails are drawn, you can try swapping their order or making adjustments to change the impact of the strip.

\section{3/1/1/2/3) layout - Sketch out the frames}

The layout should guide the reader's eyes naturally through the panels. Always remember that readers will move from left to right, top to bottom, except when reading manga which is read from right to left like Arab language in this study. Use different sizes and shapes for panels to help guide the reader (Inner Space, 2007). Remember that a reader's eyes will move from left to right and top to bottom, so structure comic's layout accordingly.

Figure (5) description: First example is a logical for English comics, demonstrating flow at its simplest. The second example flows equally well for Arabic comics, in both examples, adds an element of interest by breaking up the composition to engage the reader a little more.
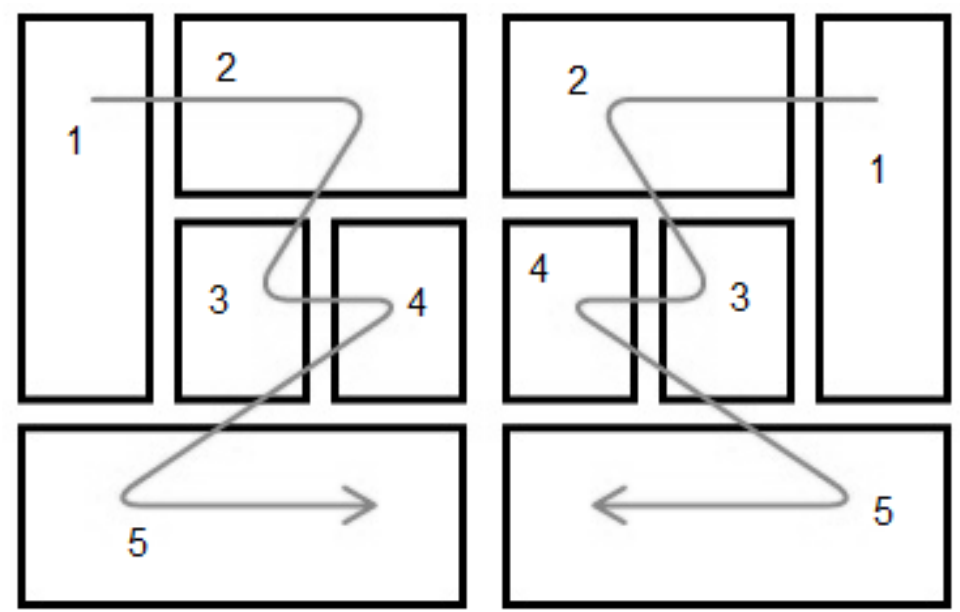

Figure (5) Comics page layout examples: English and Arabic layout examples 


\section{3/1/1/2/4) add text}

Text can be used in many different types. These include:

- A speech balloon or the bubble is a speech indicator, containing the characters' dialogue. Thought bubbles for a character's inner thoughts.

- Sound Effects: Sound can be displayed using sound effect words, or Exclamations can occur outside of regular speech bubbles to add extra impact.

- Captions: Narration boxes allow a narrator to set up a scene or describe some aspect of the story.

Some software programs like Comic Life, Manga Studio, and Adobe Illustrator is a useful application for building comics owing to its layout, and text features as well as all the illustrative bells and whistles it has. In previous figure (3), we can observe the different forms and text containers. 3/1/1/2/5) Evaluation \& Validation of Design Steps

Self-review for all of the previous steps, script, sketch, layout, text. Show all the outputs of the design process to experts to evaluate them. 3/1/1/3) Comics Development

Drawing the Comic by "3D Studio Max" and "Comic Life 3" software.

\section{3/1/1/3/1) Create the Frames}

In this study, Web comics can be any size you would like, though you should keep in mind the typical viewer's display size. If you make comic visible on a monitor with a resolution of $1024 x 768$, most users will not have an issue (Evoluted New Media, 2005). As of today (2014), 99\% of 
website visitors have a screen resolution of $1024 \times 768$ pixels or higher (W3Schools.com, 2014).

On Web comics, many viewers will not enjoy web-browser scrolling left and right in a web page to view a comic. Keep this in mind when laying out the comic. Scrolling up and down in web-browser is typically much more acceptable (Wikihow, 2014). But in this study the author used 3D Max viewports for drawing image, it can adjust the measurement of choice "Unit Setup".

3/1/1/3/2) Create Images

Begin comic drawing with a light pencil so that you can easily erase and make adjustments. Continue adjusting drawing until you have the outline for final ink. Remember to leave space for dialogue. Leave blank space to include dialogue bubbles, thought bubbles, narration boxes, exclamations, and sound effect words so that they can easily be added in later.

- Create Objects and Scene "Modeling": Modeling can be performed by means of a dedicated program (e.g., Cinema 4D, Maya, Blender, Light wave, 3DS Max), the author used 3DS Max in this study. 3D modeling is used in various industries like films, animation and gaming, interior designing, architecture and comics. The model describes the process of forming the shape of an object. The two most common sources of 3D models are those that an artist or engineer originates on the computer with some kind of 3D modeling tool, and models scanned into a computer from real-world objects. Models can also be produced procedurally or via physical 
simulation. Basically, a 3D model is formed from points called vertices (or vertexes) that define the shape and form polygons.

- Create Material and Color "Texture Mapping": 3D Materials including Full Color to Plastic, Metal, Ceramics, Wax, and more, 3D max covers all product material needs. Texture mapping is a method for adding detail, surface texture (a bitmap or raster image), or color to a computer-generated graphic or 3D model.

- Create Light And Shadow: Shadows are created by testing whether a pixel is visible from the light source, by comparing it to a z-buffer or depth image of the light source's view, stored in the form of a texture.

- Create Camera: Create Camera from View creates a Target camera whose field of view matches an active Perspective viewport. At the same time, it changes the viewport to a Camera viewport for the new camera object, and makes the new camera the current selection. (Autodesk, 2014)

- Create Animation: Before rendering into an image, objects must be placed (laid out) in a scene. This defines spatial relationships between objects, including location and size. Animation refers to the temporal description of an object, i.e., how it moves and deforms over time. Popular methods include key framing, inverse kinematics, and motion capture. These techniques are often used in combination. As with modeling, physical simulation also specifies motion.

\section{3/1/1/3/3) Render Image}

Rendering converts a model into an image either by simulating light transport to get photo-realistic images, or by applying some kind of style as

\section{r^}


in non-photorealistic rendering. Rendering in $3 \mathrm{D}$ max software, is the 3D computer graphics process of automatically converting 3D wire frame models into 2D images with 3D photorealistic effects or non-photorealistic rendering on a computer, for using it in comics.

There are many 3ds Max users who have trouble with the final render output. They don't know how to print the final image with the correct DPI (dots per inch) value that is good for layout of A1 or A3 paper in Photoshop. Some of them try to render a large image, but it really take a lot of time to finish. The others have to render out and save the final image as TIFF file with 300dpi value. Remember that this way you may have the final image with a small size. So, I would like to inform you there is a choice of the render output in 3ds MAX. We call it as Print Size Wizard (Nhan Design, 2012).

In the list of Paper Size below for more information. Render picture in at 300 or 600 DPI (dots per inch). This resolution will keep images lines intact and crisp looking, higher resolution with 300 or 600 DPI, we can use it in web comics. For size example:

- 300dpi for A4 - 297x210mm Paper Size, the image size is $3507 \times 2480$

- 300dpi for A3 - 420x297mm Paper Size, the image size is $4960 \times 3507$

- 300dpi for A2 - 594x420mm Paper Size, the image size is $7013 \times 4960$

- 300dpi for A1 - $841 \times 594 m m$ Paper Size, the image size is $9933 \times 7015$ 
- 300dpi for A0 - 1189x $841 \mathrm{~mm}$ Paper Size, the image size is $14043 \times 9933$

\section{3/1/1/3/4) Clean Up the Image}

We can clean up the Images or render frames by Photoshop, if any problems found. Once you have the drawn comic scanned, you can use Photoshop to erase small mistakes or pencil lines that you may have missed. You can use Photoshop tools to add extra shading and stronger lines as well (Wikihow, 2014; Florence, 2014).

3/1/1/3/5) Starting Work in Comics Software "Comic Life 3"

- Add Images in Panel Layout: In previous figure (1) show the basic Comics layout in "comic life" tool, the author use it in this study.

- Add balloons, captions and Sound Effects: In previous figure (2), the three main text elements, balloons, captions and Sound Effects, can be easily added to comic pages.

- Add Text: A comic's text can help comic stand out and set it apart from others. Try out different font styles make comic unique. Create a font that complements the tone of the writing as well as the visual style. You can also use different fonts for different characters, though too many variations can become distracting (Wikihow, 2014; Florence, 2014). There are a wide variety of fonts on "comic life $3 "$ program, both for free with 45-day trial, and for purchase. Author also can choose to add dialogue or speech bubbles in usage program "comic life 3". The text should be on top, followed by the bubble, followed by the original drawing on the bottom. 
- Color: As many successful comics are colored or in black and white. There are options when coloring comics. Author can choose color style into a computer software.

- Save and export the comic: the author uses the "Save" and "Save as" selections, when he finishes work section. The default save option for Comic Life 3 is the Comic Archive document. The file extension is ".comic life". This format will allow you to save, reopen and continue working on comic project at a later time. In a "comic life 3 " software, export is to convert a file into another format than the one it is currently in. Once the file is exported to the desired format (specified in its file name suffix) (Rouse, 2005), it can be opened and worked on by an application that recognizes and uses this format. A "comic life 3" software use this term. This software let the Author export a comic file by simply specifying the appropriate file name suffix, can export comic in a variety of ways. Comic Life 3 has export directly ePub as well as CBZ format for those who want to publish comics. Export directly to Facebook or Email to share comics with friends. For print quality options you can export comic as a high resolution PDF or image file. We can show the export types in next figure (6).

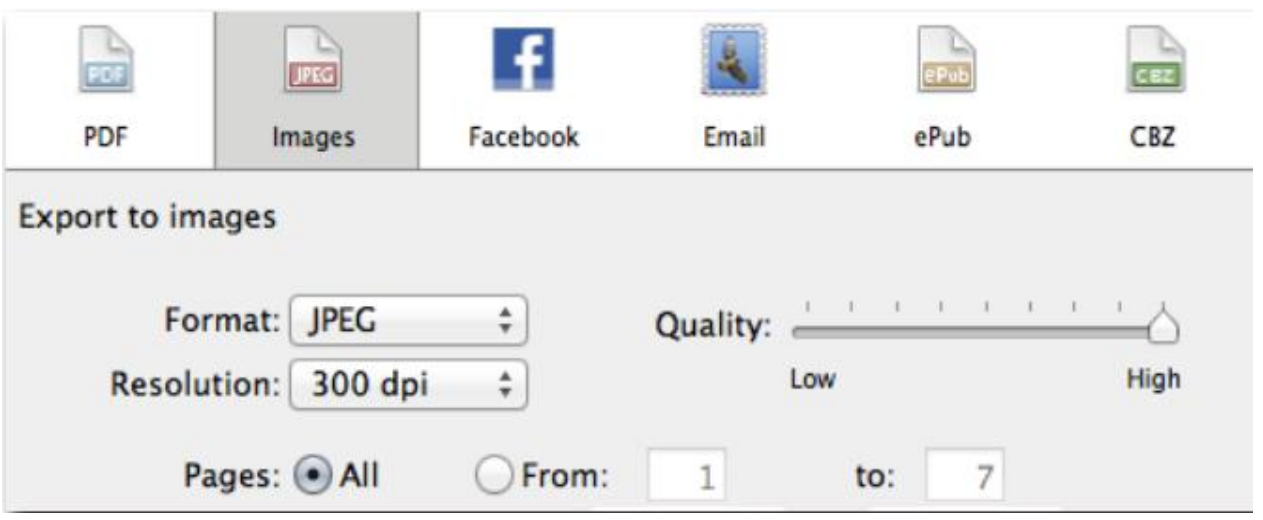


Figure (6) export options in comic life 3

\section{3/1/1/3/6) Evaluation \& Validation of Development Steps}

Self-review for all of the previous steps, with a note that in comic, the first step in drawing method is creating the frames, then add content to frames, draw final lines by Ink, scan and clean comic on a computer, create font, add dialogue, speech bubbles and Coloring.

3/1/1/4) Comics Publishing

3/1/1/4/1) Upload to an image host and spread the links

If you just want to share comic with some friends and family, uploading it to an image host will be the cheapest (free) and easiest way to do it. Create an account with a service like PhotoBucket, ImageShack, or imgur and upload creation. Send the links to whoever you want, post them on social network feeds, tweet the URL to anyone who will read it. Find comic enthusiast forums and post links for people all over the world to see (Wikihow, 2014; Florence, 2014).

\section{3/1/1/4/2) Self Publish Comic - Create Web Comic Page}

Create a website that looks good. If the website does not function properly and does not match the aesthetic of comic, you will drive users away. Take some time and look at how successful web comics have integrated the style of the comic into the website design. Interact with readers. Beyond simply updating the page with new comics, take some time, write blog entries, and respond to reader comments. This will help advertise you as the creator and form strong bonds between you and audience (Wikihow, 2014; Florence, 2014). The publisher here is the author himself, we can show www.salem4it.com main page, it web-comics platform in this study in figure (7). 


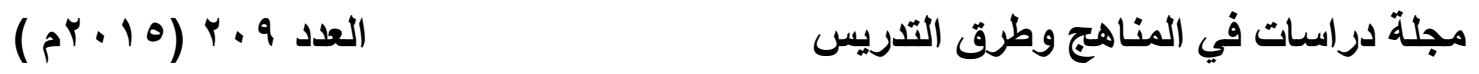

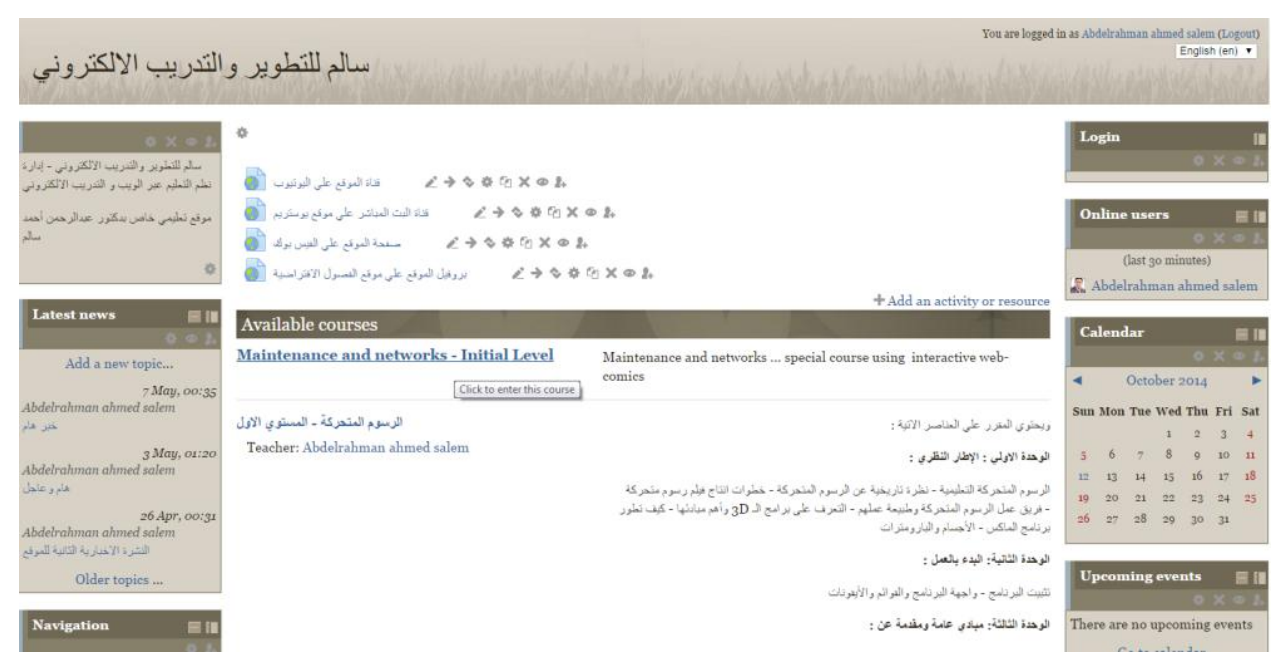

Figure (7) www.salem4it.com, web-comics base in "Salem 4 IT" website

But if creator cannot create special web site. Can use Resources such as Amazon's CreateSpace, allow authors to publish easily. CreateSpace will automatically list comic on Amazon, and will print copies to match orders. This takes a lot of the manufacturing and distributing work off shoulders.

3/1/1/4/3) Evaluation \& validation of Publication steps

Review all the previous steps, with a note in creating own web comic page, the website requires specific criteria and steps.

- Get Domain Name

- Choose a Web Host and Sign Up for an Account

- Designing Web Pages

- Uploading comics files

- Creating Web communication Activities

- Testing Website

- Collecting Information from visitors

- Getting Site Noticed 
Any way, the author can show the general steps for Comics development life cycle in next figure (8), which the author followed in this study.

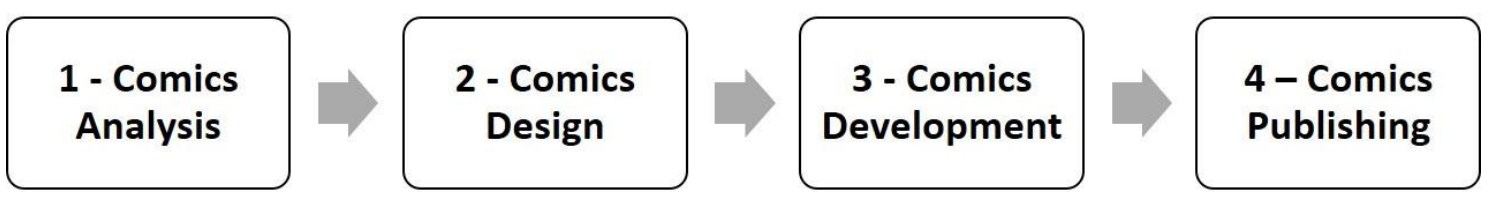

Figure (8) Proposed Model - General Steps for Comics development life cycle

Also the author determines the detailed steps of these stages as Proposed Model shown in next figure (9), which the author explanation it in previous pages, of the proposed production model details and its criteria and standards.

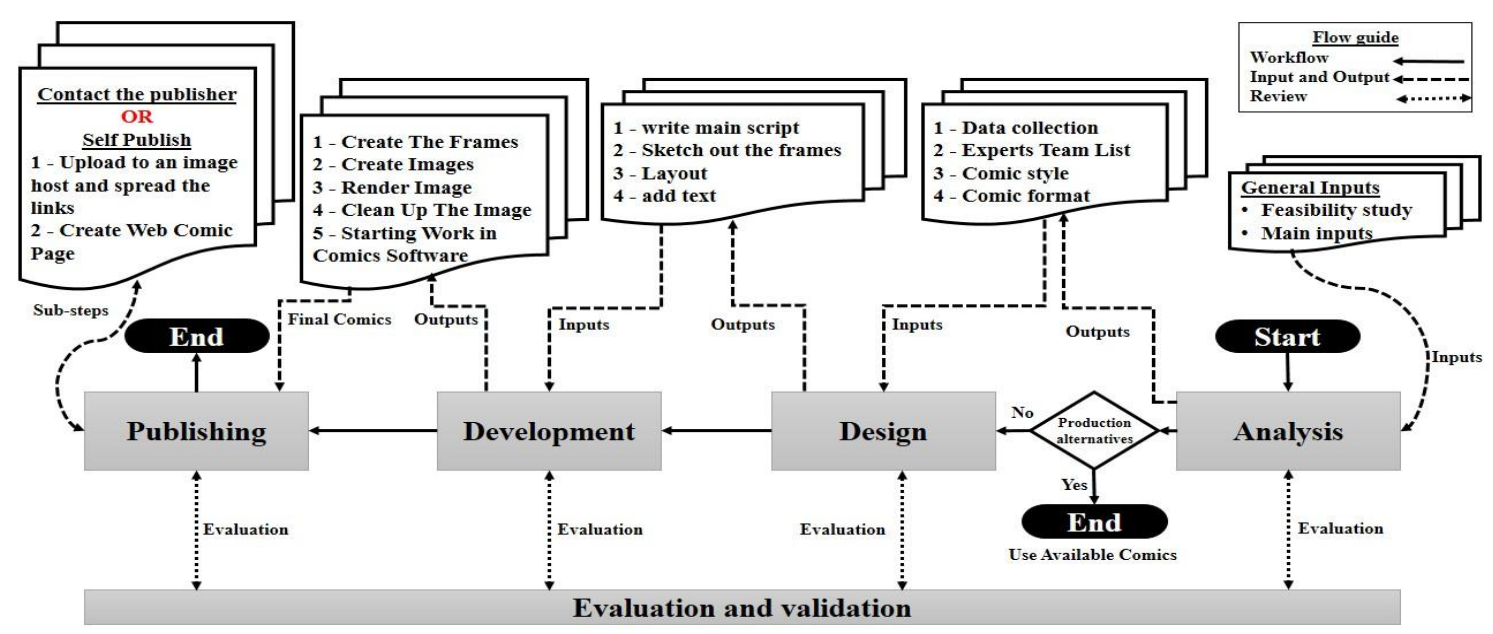

Figure (9) Proposed Model - Sub Steps

3/2) Building study tools and measurement and validation

3/2/1) Achievement test

An e-test on the Web in the Learning Management System (www.salem4it.com), aims to measure the cognitive part of the targeted skills in the study for the sample. 
This achievement test is divided into two parts. First: tick $(\sqrt{ })$ in front of the correct answer in the answer sheet, Second: Choose the correct answer, then tick $(\sqrt{ })$ in front of the correct answer in the answer sheet. In general, the achievement test contains 10 questions with a total score of 10 points.

\section{3/2/2) skill performance checklist}

A skill performance checklist test is a Card on paper, aims to measure the skill performance part of the targeted skills in the study for the sample by observation. In general, a skill performance checklist contains 10 skills with a total score of 10 points by average.

This skills is:

1. Turn Off the computer and unplug all wires connected to the tower and if there is a power switch on the back switch it off.

2. Take out the screws on the back of the tower, take out the panel, then wear an anti-static wrist strap to protect components by ear thing your static electricity, and then take out the motherboard tray.

3. Take the motherboard and screw it on to the motherboard tray then slide it back into the case.

4. Firmly insert RAM (Random Access Memory) sticks into the long and narrow slots usually located at the top right of the motherboard.

5. Carefully place the CPU into the socket that is square shaped on the motherboard then place the CPU fan on top.

6. Look for a slot about the length of your middle finger and has very small lever. 
7. Slowly slide the hard drive into the hard drive bay usually located at the front of the tower then connected the cables from the back of the hard drive to the motherboard.

8. Drives are similar to hard drives, just slide it into the bay at the top (right or left depending on the panel that was open) and connect the wires.

9. For audio devices match the colors and USB is pretty much self-explanatory.

10.If student have a video card the back of it should be sticking outside which is where you connect the monitor cable to, unless there is no video card then you connect to the motherboard.

It helps to ensure consistency and completeness in carrying out a task for learners. It was designed according to a Likert scale, the format of a typical five-level Likert item, for example, could be:

1. Strongly disagree

2. Disagree

3. Neither agree nor disagree

4. Agree

5. Strongly agree

\section{3/2/3) Educational Web-comics page:}

In Appendix (3) in Appendices, or in the $\mathrm{CD}$ accompanying the study, or visiting www.salem4it.com website, we can show pdf comics tools in this study.

3/3) Procedure exploratory experiment 
Exploratory experiment conducted on a group of 20 students, selected as study sample, they've been applied to measurement tools, materials and experimental processing, and in accordance with the following procedures:

Author prepared an explanation of the idea of comics, was to clarify the objectives of producing comics for the students of the exploratory sample.

Each student studying educational content and then applied to the achievement test and skill performance checklist.

Has been monitoring the results of the achievement test and skill performance checklist, where we can calculate the coefficients ease and difficulty, excellence and ensure validity and reliability of the tests. As experience has enabled us to calculate the time of the tests.

3/4) Procedure the study experience

3/4/1) Experimental Design

Table (1) the experimental design

\begin{tabular}{c|c|c}
\hline & \multicolumn{2}{|c}{ Interactive Levels } \\
\cline { 3 - 3 } achievement & Web Comics & Visual Comics \\
\hline performance skills & & G2 \\
\hline
\end{tabular}

In table (1) the experimental design, in tables Appendix, we can find the relation between Independent variables and Dependent variables, in this study.

- Interactive Levels (Independent variables)

- Visual Comics (Presentation Mode)

- Web Comics (Hyperlinked Mode)

- Students Skills (Dependent variables) 
- Achievement

- Performance skills

\section{3/4/2) Study Limits}

The study is confined to the following limits:

- Participants: The study is limited to the practical aspect of computer upgrade and maintenance course for 40 students of the First year in Educational technology department, in faculty of Specific education, Port Said - Egypt.

- Time: The suggested program applied in the first semester from study year 2014.

3/4/3) procedure the study experiment

To investigate the study objectives, the author prepared some tools:

- Achievement test

- skill performance checklist

- Educational Web-comics page

- graphical Visual Comics based on web "presentation"

- graphical Hyper Comics based on web "reading"

In photos (1), (2), (3) and (4) in Appendix, the photos shows students during the experiment in group 1 and group 2. The experiment was performed according to the following steps :

- Choose a sample of the study population

- Making sure that the final scheduled is ready for Applying.

- Apply the pre-test and skill performance checklist and monitoring their grades by observation.

- Apply experience on the experimental groups simultaneously. 
- Apply post-testing and skill performance checklist and monitor their grades by observation.

\section{4) Results:}

\section{4/1) Statistical Method}

Statistical method used in the study is T - TEST. Is more suitable for processing data and statistical methods, according to the experimental design of the study, as well as the sample size and the number of member, 20 students in each group.

4/2) Statistical Results

The author input the student's degrees of experimental groups in SPSS Program to calculate the statistical result. In table (2) in tables Appendix, we can find the Statistical results to T - TEST - Group Statistics.

Table ( $($ ) Statistical results to T - TEST - Group Statistics

\begin{tabular}{|c|c|c|c|c|c|}
\hline & Comics & $\mathrm{N}$ & Mean & $\begin{array}{c}\text { Std. } \\
\text { Deviation }\end{array}$ & $\begin{array}{c}\text { Std. Error } \\
\text { Mean }\end{array}$ \\
\hline \multirow{2}{*}{$\begin{array}{c}\text { Achievemen } \\
\mathbf{t}\end{array}$} & Web Comic & 20 & 8.7000 & .65695 & .14690 \\
\hline & Visual Comic & 20 & 9.3500 & .58714 & .13129 \\
\hline \multirow[b]{2}{*}{ Skills } & Web Comic & 20 & 8.1500 & .36635 & .08192 \\
\hline & $\begin{array}{l}\text { Visual } \\
\text { Comic }\end{array}$ & 20 & 9.3500 & .48936 & .10942 \\
\hline
\end{tabular}

And we can find Independent Samples Test in table (3) in tables Appendix.

Table ( $\left.{ }^{r}\right)$ Statistical results to T - TEST - Independent Samples Test

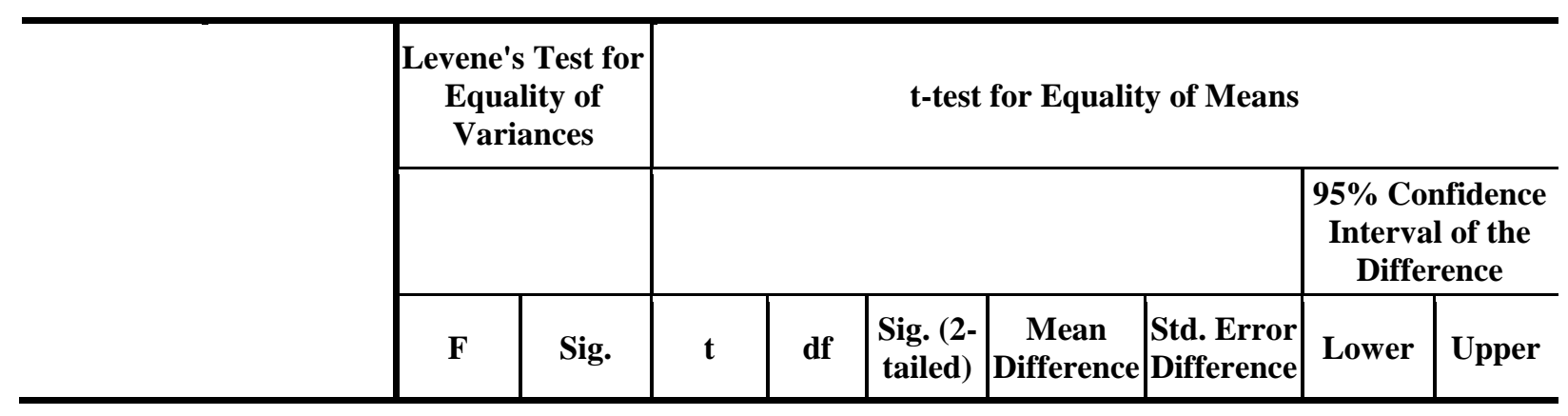




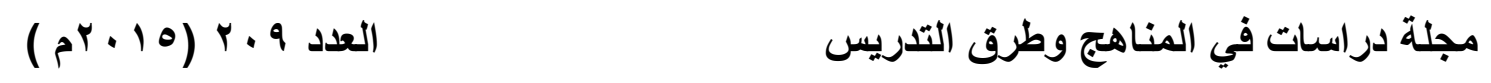

\begin{tabular}{|c|c|c|c|c|c|c|c|c|c|c|}
\hline $\begin{array}{c}\text { Achieveme } \\
\text { nt }\end{array}$ & $\begin{array}{l}\text { Equal } \\
\text { variances } \\
\text { assumed } \\
\text { Equal } \\
\text { variances } \\
\text { not assumed } \\
\end{array}$ & .198 & .659 & $\begin{array}{l}-3.299 \\
-3.299\end{array}$ & $\begin{array}{c}38 \\
\\
\begin{array}{c}37.53 \\
0\end{array}\end{array}$ & $\begin{array}{l}.002 \\
.002\end{array}$ & $\begin{array}{l}-.65000 \\
-.65000\end{array}$ & $\begin{array}{l}.19702 \\
.19702\end{array}$ & $\begin{array}{l}-1.04884 \\
-1.04900\end{array}$ & $\begin{array}{l}-.25116 \\
-.25100\end{array}$ \\
\hline \multirow{2}{*}{ Skills } & $\begin{array}{l}\text { Equal } \\
\text { variances } \\
\text { assumed }\end{array}$ & 9.162 & .004 & -8.779 & 38 & .000 & -1.20000 & .13669 & -1.47671 & -.92329 \\
\hline & $\begin{array}{l}\text { Equal } \\
\text { variances } \\
\text { not assumed }\end{array}$ & & & -8.779 & $\begin{array}{c}35.20 \\
6\end{array}$ & .000 & -1.20000 & .13669 & -1.47744 & -.92256 \\
\hline
\end{tabular}

On the statistical results tables shows us that the average degrees of students who learned using visual comics were greater than the average scores of students who learned using the web comics. It also shows the same tables that significance (.002) and collectible (.000) for the performance of the skill level, which is less than the specified values (0.05), which means that the proposed strategy has achieved positive results, as shown in the interpretation of the results in the following pages.

Extrapolating the results in statistical analysis tables, table (2) and (3), it is clear that it amounted to an average value of the groups, who teaches students by Web Comics (8.7000) and groups who teaches students by Visual Comics (9.3500) in achievement tests.

- Accordingly, first hypothesis was rejected, and reformulated as follows: "There are differences with statistical significance at level (0.05) in the experimental students score average at the achievement tests of the targeted skills, due to main effects of educational comics styles (Web Comics - Visual Comics), in favor of the Visual Comics.“

Extrapolating the results in statistical analysis tables, table (2) and (3), show that the average amount of the groups, who teaches students by 
Web Comics (8.1500) and groups who teaches students by Visual Comics (9.3500) in skill performance checklist.

- Accordingly, second hypothesis was rejected, and reformulated as follows: "There are differences with statistical significance at level (0.05) in the experimental students score average at the skill performance checklist of the targeted skills, due to main effects of educational comics styles (Web Comics - Visual Comics), in favor of the Visual Comics.“

\section{5) Discussion / Conclusion:}

The author explains that, based on the educational theories and previous studies, as follows:

The Cognitive Theory of Multimedia Learning model in next figure (10), describes the cognitive science principles of effective multimedia educational technology use in e-learning.

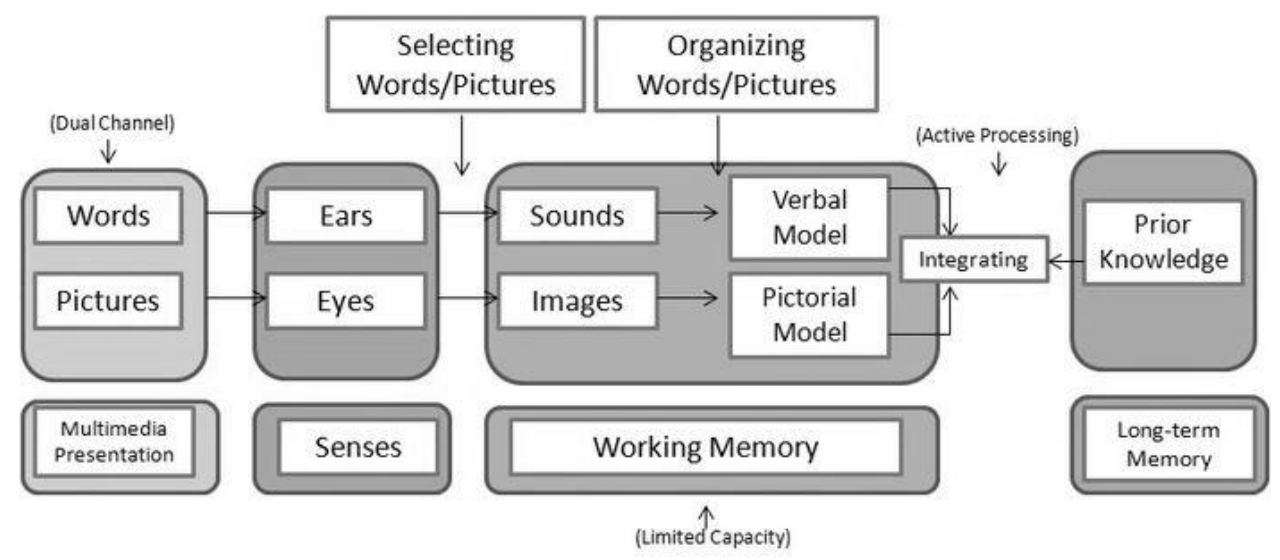

Figure (10) Mayer (2001) the cognitive theory of multimedia learning model.

Cognitive research and theory suggest that selection of appropriate concurrent multimedia modalities may enhance learning, as May application of several other principles. Richard E. Mayer's "modality 
principle" states that if materials contain both verbal and graphical information, the verbal information should be given in auditory format only, and not as written text as well. "Mayer" found that "Students learn better from animation and narration than from animation, narration, and onscreen text". (Mayer, \& Moreno, 1998; Mayer, \& Moreno, 1999; p.p. 358368; Mayer, 2001; Ginns, 2005). For that the presentation mode in Visual Comics using animation, sound effects and narration, accomplishes the best educational results and encourages students to learn.

The theories of learning like Social learning theory, Constructivism learning theory, behaviorism learning theory and E-learning theory Conform that; Using educational comics with educational webpages, focuses on the environmental and social aspects which can stimulate learning. Interaction with other people, collaborative discovery and the importance of peer support as well as pressure. Mode Neutral Convergence or promotion learning where online and classroom learners can coexist within one learning environment thus encouraging interconnectivity and the harnessing of collective intelligence. By using newer generation web 2.0 services (Black, \& McClintock, 1995; Smith, Reed, \& Jones, 2008; Tam, \& Eastwood, 2012). For that the web based learning, accomplishes the best educational results and encourages students to learn.

For these reasons, the author mixed Visual Comics, multimedia and web learning, to accomplish the best educational results of this study. According to the results, the author recommends:

- Use presentation in Visual Comics when we target the achievement objectives or the skill performance objectives. 
- Mixing and using the suggested educational Comics styles, reading in Web Comics and presentation in Visual Comics, accomplishes the best educational results and encourages students to learn.

- Don't ignore the other styles which weren't used in this study, like (printed Photo Comics, Hyperlink Photo Comics, Photo Visual Comics, and interactive Photo Comics). The author recommended that it's important to use this styles in other studies to known its effects.

- The author recommend to show the deference between educational Visual Comics and animation in other studies for knowing the deference and its effects.

- Do not neglect the Benefits of web based in comics, provided by the e-learning environment, and using social network and web2 activities, due to its importance for both teachers and learners. 


\section{References}

Abdel-Salam, M. (2012). Educational program using the kinetic story comic and its impact on basic motor skills for kindergarten. Unpublished MA. Dissertation, Faculty of Physical Education for Girls, Zagazig University.

Ali, M. (2007). The effectiveness of comic stripes in modifying some health related misbehaviors and developing awareness of them among hearing impaired students at primary stage. Unpublished MA. Dissertation, College of Education, Banha University.

Autodesk. (2014). Create Camera from View. Retrieved Dec 16, 2014, from http://knowledge.autodesk.com/support/3ds-max/learnexplore/caas/CloudHelp/cloudhelp/2015/ENU/3DSMax/files/GUID357BE338-6CCE-403B-B719-17B13A72B442-htm.html

Badr, E. (2010). The role of children magazines stories in developing of the social behavior of the Egyptian child. Unpublished MA. Dissertation. Ain Shams University: Faculty of Information and Culture of children.

Black, J., \& McClintock, R. (1995). An Interpretation Construction Approach to Constructivist Design.

Butler, T. (2014). Making a comic. Retrieved May 27, 2014, from http://www.lackadaisycats.com/makingacomic.php.

Carrier, D. (2001). The Aesthetics of Comics. Penn State Press. ISBN 9780-271-02188-1.

Creative Comic Art (2014) Comic Panels and Comic Layout. http://www.creativecomicart.com/comic-panels--layout.html.

Dawson, W. (2010). Lila \& Ecco's Do-It-Yourself Comics Club. Kids Can Press Ltd. ISBN 978-1-55453-438-8. 
Dibell, A. (1988). Plot. Cincinnati, OH: Writer's Digest Books. ISBN 089879-303-3. *Kernen, Robert (1999). Building Better Plots. Cincinnati, Ohio: Writer's Digest Books. p. 51. ISBN 0-89879-903-1.

Dorrell, L., Curtis, D., \& Rampal, K. (2004). Book-Worms without Books? Students Reading Comic Books in the School House. http://dx.doi.org/10.1016\%2Fj.endeavour.2004.07.003.

Duncan, R., \& Smith, M. (2009). The Power of Comics. Continuum International Publishing Group. ISBN 978-0-8264-2936-0.

Eisner, W. (1985). Comics \& Sequential Art. Poorhouse Press. ISBN 9780-9614-7281-8.

Eisner, W. (1996). Graphic Storytelling and Visual Narrative. Poorhouse Press. ISBN 978-0-9614728-2-5.

Evoluted New Media (2005). Standard' sizes in webcomics. The Webcomics List, http://www.thewebcomiclist.com/forums/viewtopic.php?t=8185

Failkawi, N. (2011). The impact of duties kinetic comic style to learn some skills basic football deaf and dumb students in Kuwait.thesis. Unpublished MA. Dissertation, Faculty of Physical Education for Girls, Zagazig University.

Florence, N. (2014). How to Draw Comics: Create a Comic Strip in 4 Simple Steps. Retrieved May 27, 2014, from https://www.udemy.com/blog/how-to-draw-comics/

Ginns, P. (2005). Meta-analysis of the modality effect. Learning and Instruction. doi:10.1016/j.learninstruc.2005.07.001

Gruenberg, S. (1944). The Comics as a Social Force. Journal of Educational Sociology, Vol. 18, No. 4, The Comics as an Educational 
Medium, pp. 204-213, Published by: American Sociological Association, Article Stable URL: http: //www.jstor.org/stable/2262693.

Hassan, R. (2009). The comic paradox: A study in the aesthetics of humor in postmodern American fiction. Unpublished Ph. D. Dissertation, Faculty of Arts, Mansoura University.

Hutchinson, K. (1949). An Experiment in the use of Comics as Instructional Material. Journal of Educational Sociology, Vol. 23, No. 4, pp. 236-245, Published by: American Sociological Association, Article Stable URL: http://www.jstor.org/stable/2264559

Inner Space. (2007). Comic Panel / Layout Tutorial. Retrieved November 06, 2014, from http://innerspace.notonigon.com/?p=8

Kaplan SAT Subject Test. (2009). Literature 2009-2010 Edition. Kaplan Publishing. p. 60. ISBN 1419552619.

Kirszner, L., \& Mandell, S. (1994). Fiction: Reading, Reacting, Writing,

Paulinas. pp. 3-4, ISBN 015501014X, retrieved February 11, 2013

Lee, S. (1978). How to Draw Comics the Marvel Way. Simon \& Schuster. ISBN 978-0-671-53077-8.

Literary devices. (2014). Onomatopoeia Definition. Retrieved December 02, 2014, from http://literarydevices.net/onomatopoeia/

Lyga, A., \& Lyga, B. (2004). Graphic Novels in your Media Center: A Definitive Guide. (1st Ed.). Libraries Unlimited. ISBN 1-59158-1427.

Markstein, D. (2010). Glossary Of Specialized Cartoon-related Words and Phrases Used in Don Markstein's Toonopedia ${ }^{\mathrm{TM}}$. Archived from the original on 2012-02-04. Retrieved February 8, 2013. 
Mayer, R. (2001). Multimedia learning. New York: Cambridge University Press. ISBN 0-521-78749-1.

Mayer, R., \& Moreno, R. (1998). A Cognitive Theory of Multimedia Learning: Implications for Design Principles.

Mayer, R., \& Moreno, R. (1999). Cognitive principles of multimedia learning: The role of modality and contiguity. Journal of Educational Psychology, Vol 91 (2): 358-368. doi:10.1037/0022-0663.91.2.358.

McCloud, S. (1993). Understanding Comics. Kitchen Sink Press. ISBN 087816-243-7.

Morrell, Jessica Page (2006). Between the Lines: Master the Subtle Elements of Fiction Writing. Cincinnati, Ohio: Writer's Digest Books. p. 64. ISBN 978-1-58297-393-7.

Morsy, A. (2004). Henry fielding theory of the comic epic in prose with particular reference to joseph Andrews and tom jones. Unpublished Ph. D. Dissertation, faculty of arts, Assiut University.

Nagata, R. (1999). Learning next term biochemistry through manga helping students learn and remember, and making lectures more exciting. Biochemical Education (Elsevier Science Ltd) 27 (4).

Negrete, A., \& Lartigue, C. (2004). Learning from education to communicate science as a good story. Endeavour 28 (3): 120-124. doi:10.1016/j.endeavour.2004.07.003. PMID 15350764.

Norton, B. (2003). The Motivating Power of Comic Books: Insights from Archie Comic Readers. Reading Teacher 57: 140-147.

Piekos, N. (2013). http://www.blambot.com/grammar.shtml. 
Pieper, C., \& Homobono, A. (2000). Comic as an education method for diabetic patients and general population. Diabetes Research and Clinical Practice 50.

Rouse, M. (2005). Definition export. Retrieved November 06, 2014, from http://whatis.techtarget.com/definition/export, September 2005.

Salem, A. (2005). Designing and producing a 3D Simulation Program That helps Developing the Basic Skills of Assembly and Maintenance for Computers, and Measuring Its Effectiveness in Teaching Students of Computer Science. Unpublished MA. Dissertation, Faculty of Education, Helwan University.

Salem, A. (2009). Characters Development in 3D's Instructional Computer Programs Based Simulation Games and Its Effects on Developing Skills Performance for the Students of Computer Teacher Department, Unpublished Ph. D. Dissertation, Faculty of Education, Helwan University.

Salem, A. (2011). The impact of the different pattern to provide interactive educational children's stories in the motivation of the development of children learning about computer. Paper presented at the $7^{\text {th }}$ annual conference of Arab Association Educational Technology on Arab peoples challenges and e-learning "Interactive learning communities". Institute of Educational Studies - Cairo University. 27-28/7.

Smith, B., Reed, P., \& Jones, C. (2008). 'Mode Neutral' pedagogy. European Journal of Open, Distance and E-learning. Retrieved May 9, 2014 , from http://www.eurodl.org/materials/contrib/2008/Smith_Reed_Jones.htm. 
Tam, C., \& Eastwood, A. (2012). Building e-learning modules using web 2.0 services. Med Teach. 2012;34 (12):1078-80. doi:10.3109/0142159X.2012.

University of Illinois: Department of English (2006). Freytag's Triangle. $\begin{array}{lllll}\text { Retrieved } & \text { May } & 9, & \text { 2014, }\end{array}$ http://www.english.uiuc.edu/lit_resources/english\%20102/miscellaneo us/freytag.htm.

University of South Carolina (2006). The Big Picture. Retrieved May 9, 2014, from http://home.earthlink.net/ mr.kilgore/102/handouts/bigpicture_what.h tm.

Versaci, R. (2001). How Comic Books Can Change the Way Our Students See Literature: One Teacher's Perspective. Vol. 91, No. 2 (Nov., 2001), pp. 61-67, Published by: National Council of Teachers of English, Article Stable URL: http://www.jstor.org/stable/822347.

W3Schools.com (2014) Browser Display Statistics. Retrieved May 9, 2014, from http://www.w3schools.com/browsers/browsers_Display.asp

Weiner, R. (2010). Graphic Novels and Comics in Libraries and Archives: essays on readers, research, history and cataloging. USA: McFarland.

Wikihow. (2014). How to Make a Comic. Retrieved May 9, 2014, from http://www.wikihow.com/Make-a-Comic

Wright, B (2001). Comic book nation: The transformation of Youth Culture in America. Johns Hopkins University Press. ISBN 0-80186514-X. 